\title{
Do G894T Polymorphisms of Endothelial Nitric Oxide Synthase 3 (NOS3) Influence Endurance Phenotypes?
}

\author{
by \\ Pawet Cięszczyk1, Marek Sawczuk2, Agnieszka Maciejewska², \\ Nijole Jascaniene ${ }^{3}$, Jerzy Eider ${ }^{1}$
}

\begin{abstract}
Endothelial nitric oxide (NO) synthase gene (NOS3) is taken into account as one of the main regulators of blood pressure and basal vascular dilation - two main factors found to be limiting for endurance performance.

We compared genotypic and allelic frequencies of the NOS3 G894T polymorphism in two groups of men of the same Caucasian descent: elite endurance athletes (rowers; $n=63$ ) and sedentary controls $(n=160)$.

We have not found any statistical difference in G894T genotype and allele frequencies in endurance orientated athletes compared to sedentary controls. The difference in $G$ allele frequency between the rowers and controls did not reach statistical significance $(73.5 \%$ vs. $67.2 \%, P=0.307)$, similar to genotype distribution amongst the rowers (58.7\% GG; 39.4\% GT; 6.4\% TT) compared to controls (43.7\% GG; $46.9 \%$ GT; $9.4 \%$ TT) $(P=0.129)$.

In summary, our results are in contradiction to the hypothesis that NOS3 G894T polymorphism is associated with the physical performance status in rowing. Of course, our findings do not mean that other polymorphisms in NOS3 gene do not have any beneficial effect on performance parameters, but to confirm that hypothesis, we need further studies.
\end{abstract}

Key words: NOS3, genotype, rowing, endurance performance

\section{Introduction}

Exercising muscles require an increased delivery of oxygen and metabolic substrates (Wolfarth et al., 2008). This is why skeletal muscle blood flow capacity and altered control of total and regional muscle blood flow may be considered one of the main factors that influence endurance performance.

One of the key substances that influences blood pressure and basal vascular tone is nitric oxide (NO) (Quyyumi et al., 1995; Kimura et al., 2003). This con- clusion is supported by Massion et al. (2003), who showed that NO in vascular endothelium regulates vasodilatation, and eventually bloood pressure. Harrison and Cai (2003) have also reported that NO physiologically regulates basal vascular tone and vascular function by inhibiting platelet and leukocyte adhesion, and by affecting the growth of smooth muscle cells.

In addition, there is strong evidence suggesting that $\mathrm{NO}$ is also involved in human skeletal muscle glucose uptake (McConell and Kingwell, 2006), as well as the modulation of oxygen consumption in

\footnotetext{
1 - University of Szczecin, Institute of Physical Culture, Poland

2 - University of Szczecin, Department of Genetics, Poland

3 - Vilnius Pedagogical University, Studentu St. 39, LT-08106 Vilnius, Lithuania
} 
skeletal muscles (Wilkerson et al., 2004). Furthermore, Shen et al. (1995) suggests that NO regulates mitochondrial metabolism to optimize the ratio between oxygen consumption and energy production.

Nitric oxide is generated by endothelial NO synthase (eNOS), a product of the NOS3 gene (Rankinen et al., 2000). This gene is situated on the 7th chromosome in locus $7 \mathrm{q} 36$ and consists of 23,530 nucleotides (Robinson et al., 1994). Several polymorphic sites have been identified within the NOS3 gene (i.e., Glu298Asp (G894T or rs1799983) in exon 7, microsatellite $(\mathrm{CA}) \mathrm{n}$ repeats in intron 13 , and $27-\mathrm{bp}$ repeats in intron $4(4 \mathrm{~B} / 4 \mathrm{~A})$ variations (Ahmetov and Rogozkin, 2009) and others. In the context of sport research, the most analyzed is the SNP G894T missense type (Glu298Asp) polymorphism within exon 7.

The G894T polymorphism is associated with exercise related phenotype traits (e.g., cardiovascular responses to exertion in the non-elite athletic population (Hang et. al., 2006; Gomez et al., 2009) and $\mathrm{VO}_{2}$ kinetics under heavy-intensity exercise (Jones et al., 2004).

Based on knowledge about the role of NOS3 G894T polymorphism in the regulation of endothelial function and blood pressure, we postulated that the genetic polymorphism of NOS3 could also influence elite endurance performance status. This hypothesis seems to be supported by Hand et al. (2006), who showed an association of the NOS3 G894T genotype with different exercise phenotypes, including heart rate, in post-menopausal women. Additionally, Sanders et al. (2006) found a significant correlation between NOS3 G894T polymorphism and actual performance during Ironman Triathlons.

According to Wang et al. (2000), the T allele of missense G894T polymorphism within NOS3 gene may be associated with reduced eNOS activity and basal NO production (and finally blood pressure). If this conclusion is valid, the GG genotype should, in theory, be more beneficial for endurance athletes than any other genotype at this polymorphic locus, as it may improves the endurance coefficients in sports people through an increase in the aerobic capacity of muscles.

The aim of this study is to perform preliminary studies to analyze the possible importance of the NOS3 gene polymorphisms in elite Polish rowers and sedentary individuals representing the possible relationships with genotype and physical performance.

\section{Materials and methods}

\section{Ethics Committee}

The Pomeranian Medical University Ethics Committee approved the study and written informed consent was obtained from each participant.

\section{Subjects and controls}

Sixty-three male Polish rowers (former and active athletes) of national competitive level were recruited for this study. Thirty-four were elite rowers, being national representatives, including world champions, with no less than ten years experience participating in sport. Additionally, 9 of the elite rowers were European Championship medalists, 7 of them were world championship medalist sand 14 of them were Olympic Games medalists. The second group of recruited athletes $(n=29)$ were non-elite rowers containing young Polish rowers (aged 18-22) who were regional competitors.

For controls, samples were prepared from 160 unrelated volunteers (male students from the University of Szczecin aged between 19-23yrs). The athletes and controls were all Caucasian to ensure no likely racial gene skew and to overcome any potential problems of population stratification.

\section{Genotyping}

The buccal cells donated by the subjects were collected in Resuspension Solution (Sigma, Germany) with use of Sterile Foam Tipped Applicators (Puritan, USA). DNA was extracted from the buccal cells using GenElute Mammalian Genomic DNA Miniprep Kit (Sigma, Germany) according to the producer protocol.

NOS3 Glu298Asp SNP (SNP 15: rs1799983): (PCR), followed by digestion with Ban II was performed. The PCR was performed in standard buffer and each 20-mL PCR test contained 100 ng genomic DNA, $0.2 \mathrm{mmol} / \mathrm{L}$ each primer, $200 \mathrm{mM}$ each dNTPs and $0.5 \mathrm{U}$ Taq polymerase. The reactions were incubated at $94{ }^{\circ} \mathrm{C}$ for $3 \mathrm{~min}, 60^{\circ} \mathrm{C}$ for $1 \mathrm{~min}$ and $72{ }^{\circ} \mathrm{C}$ for $1 \mathrm{~min}$, followed by 35 cycles of $94{ }^{\circ} \mathrm{C}$ for $30 \mathrm{~s}$, annealing at $60{ }^{\circ} \mathrm{C}$ for $30 \mathrm{~s}$ and extension at $72{ }^{\circ} \mathrm{C}$ for 45 $\mathrm{s}$ and finally one cycle of $72{ }^{\circ} \mathrm{C}$ for $10 \mathrm{~min}$. The PCR product was digested with $5 \mathrm{U}$ at $37{ }^{\circ} \mathrm{C}$ for $4 \mathrm{~h}$. The resulting fragments were separated on $2.5 \%$ acrylamide gel and visualized under UV light after ethidium bromide staining. 
Table 1

Genotype and allele frequencies of NOS3 G894T. This date is presented as absolute and relative values (within parentheses). P value corresponds to comparisons in genotype and allele frequencies within groups.

\begin{tabular}{llccccccc}
\hline \multirow{2}{*}{ Group } & \multirow{2}{*}{$\mathrm{N}$} & \multicolumn{3}{c}{ NOS3 genotype } & \multirow{2}{*}{$P$} & \multicolumn{2}{c}{ NOS3 allele } & \multirow{2}{*}{$P$} \\
\cline { 7 - 9 } & & GG & GT & TT & & G & T & \\
\hline All rowers & 63 & $37(58.7 \%)$ & $22(34.9 \%)$ & $4(6.4 \%)$ & 0.129 & $96(76.2 \%)$ & $30(23.8 \%)$ & 0.062 \\
Elite rowers & 34 & $19(55.9 \%)$ & $12(35.3 \%)$ & $3(8.8 \%)$ & 0.417 & $50(73.5 \%)$ & $18(26.5 \%)$ & 0.307 \\
Non-elite rowers & 29 & $18(62.1 \%)$ & $10(34.5 \%)$ & $1(3.4 \%)$ & 0.163 & $46(79.3 \%)$ & $12(20.7 \%)$ & 0.066 \\
Controls & 160 & $70(43.7 \%)$ & $75(46.9 \%)$ & $15(9.4 \%)$ & - & $215(67.2 \%)$ & $105(32.8 \%)$ & - \\
\hline
\end{tabular}

\section{Statistical analysis}

Genotype distribution and allele frequencies between the groups of athletes and controls were compared and significance was assessed by $\chi^{2}$ test using STATISTICA 8 statistical software. $P$ values of $<0.05$ were considered statistically significant.

\section{Results}

NOS3 genotype distributions amongst subjects and controls were in Hardy-Weinberg equilibrium, making selection bias less likely. Genotype distribution results of the control group (GG-43.75\%; GT$46.88 \%$; TT-9.38\%) were similar to those reported in previous studies on Caucasian populations (Wolfarth et al., 2008; Allanore et al., 2004). The distributions of the NOS3 genotypes and alleles are given in Table 1.

Allele frequencies of NOS3 G894T did not differ between elite rowers and sedentary controls $(73.5 \%$ vs. $67.2 \%, p=0.307$ ). As shown in Table 1 , the difference in allele frequency between non-elite rowers and controls also did not reach statistical significance, however in this case the disproportion was visibly bigger $(79.5 \%$ vs. $67.2 \%, p=0.066)$. The same trend of a higher, yet not significant allele proportion, was noted over the whole cohort of athletes, compared to sedentary controls $(76.2 \%$ vs. $67.2 \%$, $\mathrm{p}=0.062)$.

NOS3 GG genotype was not more prevalent in the group of endurance athletes than in the controls, as was theoretically suspected. The genotype distribution (Fig. 1) amongst the whole cohort of rowers (58.7\% GG; 39.4\% GT; 6.4\% TT) was not significantly different to that amongst sedentary controls $(43.7 \%$ GG; $46.9 \%$ GT; $9.4 \%$ TT) $(p=0.129)$. More importantly, in the case of the elite rowers, the proportion of NOS G894T genotype was even more similar to sedentary controls $(\mathrm{p}=0.417)$, clearly opposite to the hypothesis mentioned in the introduction of this article.

\section{Discussion}

The articles concerning the NOS3 gene in a sport context are still unique. Moreover, till now any hypothesis referring the role of this gene in physical performance status has not been clearly proven.

According the Bray et al. (2009), the NOS3 gene is one of the candidate genes explaining individual variations in health and exercise capacity-related phenotypes because it encodes the eNOS enzyme, which catalyses the synthesis of nitric oxide (NO). Since the discovery of NO in the early 1980s, this molecule was associated as playing a pivotal role in the regulation of important systems and functions in the human organism. As was mentioned in the introduction of this article, NO regulates blood pressure (Massion et al., 2003) and basal vascular tone (Quyyumi et al., 1995), which determinate the blood supply to working muscles (Heydemann and McNally, 2009). NO is also involved in the modulation of oxygen consumption in skeletal muscle (Wilkerson et al., 2004) and glucose uptake into working muscle fibers (McConell and Kingwell, 2006). Additionally, nitric oxide (NO) plays an important role in cardioprotection (Otani 2009) and myocardial respiration (Loke et al., 1999). Finally,

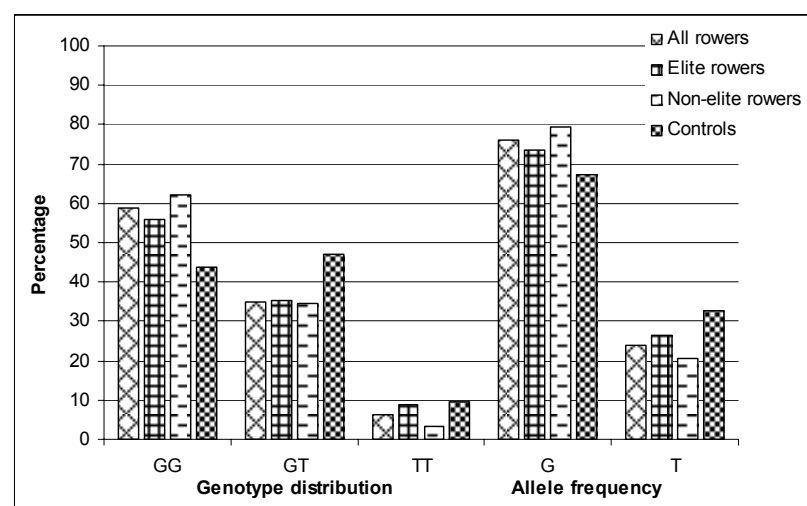

Figure 1

The NOS3 G894T genotype and allele frequencies in all groups 
there are suggestions that $\mathrm{NO}$ regulates mitochondrial metabolism to optimize the ratio between oxygen consumption and energy production (Shen et al., 1995). In this context, it is worth mentioning investigations by Jones et al. (2004), which showed that pharmalocological NOS inhibition led to significant speeding of $\mathrm{VO}_{2}$ kinetics.

Few reports have shown that the NOS3 G894T genotypes are associated with predispositions to physical performance, including top endurance-orientated athletes. Sanders et al. (2006) found a correlation between NOS3 G894T polymorphism and actual performance during Ironman Triathlons. This finding seems to be supported by Hand et al. (2006), who also showed an association of the NOS3 G894T genotype with different exercise phenotypes. On the other hand, Wolfarth et al. (2008) found no association between NOS3 G894T variation and elite endurance performance, although it did show a significant association between $\mathrm{VO} 2 \mathrm{max}$ and genetic NOS3 variation.

Our results are in opposition to observations of Sanders et al. (2006) and Hand et al. (2006). We have not found any statistical difference in G894T genotype and allele frequencies in endurance orientated athletes compare to sedentary controls. Summarizing, we have reached a similar conclusion to Wolfarth et al. (2008). These findings seem to be additionally supported by Rankinen et al. (2000), who stated that there is no data available on associations between the NOS3 G894T polymorphism and plasma NO metabolite levels.

On the other hand, the same author had a hypothesis that, although NOS3 G894T polymorphism doesn't play a role in short-term response to a single bout of exercise, it may be a significant factor in the long-term adaptation of hemodynamic phenotypes to endurance training (Rankinen et al., 2000). In this context, the G allele of NOS3 G894T polymorphism could be a marker for sedentary individuals, who are most likely to benefit from endurance training in terms of reduction in the hemodynamic load.

The role of NOS3 gene in sport status seems to be still unclear. Even if NOS3 G894T polymorphism is not correlated with a predisposition to sport performance, there are several polymorphisms in the NOS3 gene under the hypothesis that these polymorphisms may change the functional properties of NO, and hereby modify the different links by which $\mathrm{NO}$ is thought to influence endurance capacity (Wolfarth et al., 2008). Also, other reports showed the association between DNA sequence variations at NOS3 locus contributes significantly to the plasma levels of NO metabolites (Tsukada et al., 1998; Gomez-Gallego et al., 2009). All of the mentioned reports appear to require confirmation by further scientific works, taking into account the physical performance parameters.

Another aspect of the NOS3 polymorphism that warrants further studies is the possible interaction with other genetic and environmental factors. Saunders et al. (2006) pointed out that the effect of the genotype GG, advantageous for endurance performance, appeared only in connection with the genotype $(-9 /-9)$ of the gene BDKRB2. In other combinations of genotypes of both genes (NOS3 and BDKRB2), the genotype GG did not show any positive correlation with an increase in sport endurance, which suggests that although the gene NOS3 may be associated with efficiency and endurance parameters, the affirmative effect of the genotype GG is masked by the genotype +9/-9 BDKBR2. Additional questions are also associated with the correlations of NOS3 gene with the muscarinic receptor type $2(\mathrm{~m} 2)$ gene and voltagegated potassium channel subfamily $\mathrm{H}$, member 2 (KCNH2) gene (Wolfarth at al., 2008). It is suspected that both these genes might be, in conditions of further linkage, disequilibrium with some functional variants that lay in the NOS3 gene (Spina et al., 1997; Borggrefe et al., 2005). Rankinen et al. (2000) has also pointed out that coding the NOS has several co-factors, such as tetrahydrobiopterin and calmodulin, which are necessary for the optimal function of the enzyme. The genes that encode these proteins are also potential candidates themselves, because of their interactions with NOS3 (Rankinen et al., 2000).

In conclusion, our results are contrary to the hypothesis that NOS3 G894T polymorphism is associated with physical performance status in rowing. Of course, our finding does not mean that other polymorphisms in NOS3 gene do not have any beneficial effect on performance parameters, but to confirm this hypothesis, we need further studies.

\section{References}

Ahmetov II, Rogozkin VA, Genes, Athlete Status and Training - An Overview in Genetics and Sports (ed: Callins M). Med Sport Sci. Basel, Karger, 2009, vol 54, pp 43-71. 
Borggrefe M, Wolpert C, Antzelevitch C, Veltmann C, Giustetto C, Gaita F, Schimpf R. Short QT syndrome. Genotype-phenotype correlations. J Electrocardiol 2005: 38: 75-80.

Bray MS, Hagberg JM, Perusse L, Rankinen T, Roth SM, Wolfarth B, Bouchard C (2009) The human gene map for performance and health-related fitness phenotypes: the 2006-2007 update. Med Sci Sports Exerc 41:35-73

Cieszczyk P., Krupceki K, Maciejewska A., Sawczuk M.: . The Angiotensin Converting Enzyme Gene I/D Polymorphism in Polish Rowers. International Journal of Sports Medicine. 2009; 30: 624-627

Gomez-Gallego F., Ruiz JR., Buxens A., Artieda M., Arteta D., Santiago Ć., Rodriguez-Romo G., Lao J.I., Lucia A., The $2786 \mathrm{~T} / \mathrm{C}$ polymorphism of the NOS3 gene is associated

with elite performance in power sports. Eur J Appl Physiol 2009 107:565-569

Harrison DG., Cai H. Endothelial control of vasomotion and nitric oxide peoduction. Cardiol Clin 2003; 21: 289-302

Hand BD, McCole SD, Brown MD, Park JJ, Ferrell RE, Huberty A, Douglass LW, Hagberg JM. NOS3 gene polymorphisms and exercise hemodynamics in postmenopausal women. Int J Sports Med 2006: 27: 951-958.

Higashi Y, Sasaki S, Sasaki N, Nakagawa K, Ueda T, Yoshimizu A, Kurisu S, Matsuura H, Kajiyama G, Oshima T. Daily aerobic exercise improves reactive hyperemia in patients with essential hypertension. Hypertension 1999: 33: 591-597.

Jones AM, Wilkerson DP, Wilmshurst S, Campbell IT. Influence of L-NAME on pulmonary O2 uptake kinetics during heavy-intensity cycle exercise. J Appl Physiol 2004: 96: 1033-1038.

Kimura T., Yokoyama T., Matsumura Y., Yoshiike N., Date C., Muramatsu M., Tanaka H., NOS3 GenotypeDependent Correlation Between Blood Pressure and Physical Activity, Hypertension 2003;41;355-360;

Long JH, Lira VA, Soltow QA, Betters JL, Sellman JE, Criswell DS. Arginine supplementation induces myoblast fusion via augmentation of nitric oxide production. J Muscle Res Cell Motil 2006, 27:577-584

Massion PB, Feron O, Dessy C, Balligand JL. Nitric oxide and cardiac function: ten years after, and continuing. Circ Res 2003: 93: 388-398.

McConell GK, Kingwell BA () Does nitric oxide regulate skeletal muscle glucose uptake during exercise? Exerc Sport Sci Rev 2006, 34:36-41

Otani H (2009) The role of nitric oxide in myocardial repair and remodeling. Antioxid Redox Signal [Epub ahead of print]

Quyyumi AA, Dakak N, Andrews NP, Gilligan DM, Panza JA, Cannon RO 3rd (1995) Contribution of nitric oxide to metabolic coronary vasodilation in the human heart. Circulation 92:320-326

Rankinen T, Rice T, Perusse L, Chagnon YC, Gagnon J, Leon AS, Skinner JS, Wilmore JH, Rao DC, Bouchard C. NOS3 Glu298Asp genotype and blood pressure response to endurance training: the HERITAGE family study. Hypertension. 2000; 36:885-889.

Robinson LJ, Weremowicz S, Morton CC, Michel T () Isolation and chromosomal localization of the human endothelial nitric oxide synthase (NOS3) gene. Genomics 1994, 19:350-357

Shen, W., Zhang, X., Zhao, G., Wolin, M.S., Sessa, W. and Hintze, T.H. () Nitric oxide production and NO synthase gene expression contribute to vascular regulation during exercise. Med. Sci. Sports Exerc., 1995, 27, 1125-1134.

Spina RJ, Turner MJ, Ehsani AA. Exercise training enhances cardiac function in response to an afterload stress in older men. Am J Physiol 1997, 272: H995-1000.

Tsukada T, Yokoyama K, Arai T, Takemoto F, Hara S, Yamada A, Kawaguchi Y, Hosoya T, Igari J. Evidence of association of the ecNOS gene polymorphism with plasma NO metabolite levels in humans. Biochem Biophys Res Commun. 1998, 245:190 -193.

Wang XL, Sim AS, Wang MX, Murrell GA, Trudinger B, Wang J () Genotype dependent and cigarette specific effects on endothelial nitric oxide synthase gene expression and enzyme activity. FEBS Lett 2000, 471:45-50 
Wilkerson DP, Campbell IT, Jones AM () Influence of nitric oxide synthase inhibition on pulmonary O2 uptake kinetics during supra-maximal exercise in humans. J Physiol 2004, 561:623-635

Williams AG, Dhamrait SS, Wootton PT, Day SH, Hawe E, Payne JR, Myerson SG, World M, Budgett R, Humphries SE, Montgomery HE. Bradykinin receptor gene variant and human physical performance. J Appl Physiol 2004, 96: 938-942.

Wolfarth B., Rankinen T., Muhlbauer S., Ducke M., Rauramaa R., Boulay M.R., Perusse L., Bouchard C. Endothelial nitric oxide synthase gene polymorphism and elite endurance athlete status: the Genathlete study. Scand J Med Sci Sports 2008, 18:485-490

Wolfarth B, Rivera MA, Oppert JM, Boulay MR, Dionne FT, Chagnon M, Gagnon J, Chagnon Y, Perusse L, Bouchard C. A polymorphism in the alpha2a-adrenoceptor gene and endurance athlete status. Med Sci Sports Exerc 2000, 32: 1709-1712.

\section{Corresponding author}

\section{Paweł Cięszczyk}

University of Szczecin, Institute of Physical Culture, Poland 40B, Piastów Str., blok 6, 71-065 Szczecin

Phone/Fax: +48 914442749

E-mail: cieszczyk@poczta.onet.pl 